University of Wollongong

Research Online

Faculty of Engineering - Papers (Archive)

Faculty of Engineering and Information

Sciences

2008

\title{
Harmonic allocation using IEC/TR 61000-3-6 at the distribution/ transmission interface
}

Victor Gosbell

University of Wollongong, vgosbell@uow.edu.au

Sarath Perera

University of Wollongong, sarath@uow.edu.au

Timothy Browne

Arizona State University

Follow this and additional works at: https://ro.uow.edu.au/engpapers

Part of the Engineering Commons

https://ro.uow.edu.au/engpapers/5402

\section{Recommended Citation}

Gosbell, Victor; Perera, Sarath; and Browne, Timothy: Harmonic allocation using IEC/TR 61000-3-6 at the distribution/transmission interface 2008.

https://ro.uow.edu.au/engpapers/5402

Research Online is the open access institutional repository for the University of Wollongong. For further information contact the UOW Library: research-pubs@uow.edu.au 


\title{
Harmonic Allocation Using IEC/TR 61000-3-6 at the Distribution/Transmission Interface
}

\author{
V. J. Gosbell, Member, IEEE, T. J. Browne, Member, IEEE, S. Perera, Member, IEEE
}

\begin{abstract}
IEC Technical Report 61000-3-6 gives principles to be applied to ensure acceptable harmonic levels in power systems. Detailed analysis methods have been developed to apply these principles to both distribution and transmission systems. At the transmission/distribution interface, it is found that transmission harmonic allocations can be as little as one third of the allocation which would be given to an equivalent distribution load. Possible adverse consequences are discussed and several modifications to avoid this mismatch are given. The recommended modification is a hybrid approach combining aspects of both the distribution and transmission allocation methods.
\end{abstract}

Index Terms-distribution systems, harmonics, IEC standards, transmission systems.

\section{NOMENClATURE}

\begin{tabular}{|c|c|}
\hline Symbol & Meaning \\
\hline BSP & Bulk Supply Point \\
\hline $\mathrm{E}_{\mathrm{Ihi}}$ & Harmonic current at pcc allocated to installation $\mathrm{S}_{\mathrm{i}}$ \\
\hline $\mathrm{E}_{\text {Uhi }}$ & Harmonic voltage at pec allocated to installation $\mathrm{S}_{\mathrm{i}}$ \\
\hline $\mathrm{FL}_{\mathrm{i}}$ & Fault level at pcc of installation $\mathrm{S}_{\mathrm{i}}$ \\
\hline $\mathrm{G}_{\mathrm{hMV}}$ & Harmonic voltage available for loads connected to MV bus \\
\hline $\mathrm{h}$ & Harmonic order \\
\hline $\mathrm{k}_{\mathrm{h}}$ & $\mathrm{h}^{\text {th }}$ harmonic allocation constant \\
\hline $\mathrm{L}_{\mathrm{hHV}}$ & HV planning level for $\mathrm{h}^{\text {th }}$ harmonic \\
\hline $\mathrm{L}_{\mathrm{hMV}}$ & MV planning level for $\mathrm{h}^{\text {th }}$ harmonic \\
\hline $\mathrm{S}_{\text {base }}$ & Base MVA \\
\hline $\mathrm{S}_{\text {crit }}$ & $\begin{array}{l}\text { Maximum load to be given an unmodified distribution } \\
\text { allocation }\end{array}$ \\
\hline $\mathrm{S}_{\mathrm{i}}$ & Maximum demand of installation being considered \\
\hline $\mathrm{S}_{\max }$ & $\begin{array}{l}\text { Maximum distorting load which would be considered for } \\
\text { connection to a transmission system in its present state }\end{array}$ \\
\hline $\mathrm{S}_{\mathrm{t}}$ & MV system MV load supply capability \\
\hline $\mathrm{U}_{\mathrm{h}}$ & $\mathrm{h}^{\text {th }}$ harmonic voltage component \\
\hline US & Upstream \\
\hline $\mathrm{Z}_{\mathrm{h} 1}$ & Fundamental impedance at pcc for load $\mathrm{S}_{\mathrm{i}}$ \\
\hline $\mathrm{Z}_{\mathrm{hi}}$ & $\mathrm{h}^{\text {th }}$ harmonic impedance at pcc for load $\mathrm{S}_{\mathrm{i}}$ \\
\hline$\alpha$ & Summation law exponent \\
\hline
\end{tabular}

\section{INTRODUCTION}

$\mathrm{D}$ EVELOMENTS in technology and new consumer products are affecting the type of equipment connected to the power system. Modern equipment increasingly draws current distorted current waveforms with significant harmonic content. This modifies the voltage waveform and utilities may find it increasingly difficult to meet harmonic standards.

V. J. Gosbell and S. Perera are with the University of Wollongong (e-mail: v.gosbell@uow.edu.au and sarath@uow.edu.au).

T. J. Browne is with Arizona State University (email: tbrowne@ieee.org).
The IEC have developed a set of guidelines to help utilities keep harmonics under control. The most important at MV levels and above is IEC/TR 61000-3-6 [1] which covers compatibility levels, planning levels, and methods for managing the connection of large disturbing customers. The procedures are fairly straightforward when applied to strong distribution systems, but are less clear regarding distribution systems with long feeders and transmission systems.

Work has been performed in Australia in developing a detailed approach, consistent with IEC principles, to these types of system [2], [3]. Different approaches are needed to the distribution and transmission systems: the first can be broken down into independent, small and relatively timeinvariant subsystems, while the transmission system needs to be studied holistically, is continually evolving, and consequently is difficult to model reliably.

The paper will summarise IEC harmonic allocation principles and the developed methods for distribution and transmission harmonic allocation. Both approaches will be applied to a test case which will highlight a difference in the allocation strategies by a much as three to one. There is thus a risk that a distribution bulk supply point can be loaded by the distributor's allocation policies to a point that threatens the transmission company's ability to manage harmonics. The paper will discuss the factors that lead to this situation and suggest methods for resolving the difficulty.

\section{SUMMARY OF IEC/TR 61000-3-6 PRINCIPLES}

Reference [1] specifies the principles which can be used for the harmonic management of distribution and transmission systems. Time-varying harmonics are specified by their $95 \%$ probability values. The details of measurement and statistical analysis are given in IEC 61000-4-7 [4]. Diversity between harmonic sources is represented by the Summation Law

$$
\mathrm{U}_{\mathrm{h}}=\sqrt[\alpha]{\sum_{\mathrm{i}} \mathrm{U}_{\mathrm{hi}}^{\alpha}}
$$

where $\alpha$ is chosen according to the harmonic order with a value of $\alpha=1.4$ for harmonics in the range $5 \leq h \leq 10$ and a value of 2 for higher order ones.

Compatibility levels are given as a reference for the setting of equipment immunity (immunity levels must be more than the compatibility level) and utility emission (planning levels must be less than the compatibility level). Since the flow of harmonic current in general is from the LV part of the power system to the HV transmission system and then into generators, the harmonic profile of a typical power system 
shows the highest voltages at $\mathrm{LV}$, reducing through the MV system to the HV system. To assist with allocating harmonic loads to different voltage levels, the planning levels are graded from higher values at $\mathrm{LV}$ to the smallest values at $\mathrm{HV} / \mathrm{EHV}$ [1]. An extract from the values adopted at present for Australia is given in Table I [2].

$$
\text { TABLE I }
$$

SELECTION OF PLANNING LEVELS (\% OF NOMINAL) USED IN AUSTRALIA

\begin{tabular}{|c|c|c|c|c|c|}
\hline \multirow{2}{*}{$\mathrm{h}$} & \multicolumn{5}{|c|}{ Voltage level } \\
\cline { 2 - 6 } & HV-EHV & $66 \mathrm{kV}$ & $33 \mathrm{kV}$ & $11 / 22 \mathrm{kV}$ & $415 \mathrm{~V}$ \\
\hline 5 & 2.0 & 2.8 & 3.1 & 5.1 & 5.5 \\
\hline 7 & 2.0 & 2.6 & 2.7 & 4.2 & 4.5 \\
\hline 11 & 1.5 & 1.8 & 1.9 & 3.0 & 3.3 \\
\hline 13 & 1.5 & 1.7 & 1.8 & 2.5 & 2.8 \\
\hline
\end{tabular}

Installations are assessed in 3 stages. The most significant part of [1] for most utilities is Stage 2, the determination of a harmonic current allocation for a specific installation, and this will be the focus of the present paper. Reference [1] is not an international standard - despite some local versions having the force of a standard - but a Technical Report. It contains principles and some suggested analysis methods, but is not a complete detailed guide for utility analysis. Two general allocation principles are given

(i). The harmonic allocation increases with maximum demand (called "agreed power" in the standard).

(ii). All customers, both present and future, have the right to a share of the harmonic allocation. The allocation shall be such, that when each customer is just drawing their full allowance, the maximum harmonic voltage just reaches the planning level.

\section{DISTRIBUTION SYSTEM HARMONIC ALLOCATION}

Reference [1] details the allocation of harmonic current to installations connected to strong distribution systems. Distribution systems generally have the following general features

- $\quad$ radial topology

- can be broken down into subsystems supplied from a substation which have weak interactions with other parts of the system

- major loads and impedances generally well known

- line capacitance not important

- little change over the period covered by a harmonic study

The principles of distribution allocation are discussed relative to the system illustrated in Fig.1.

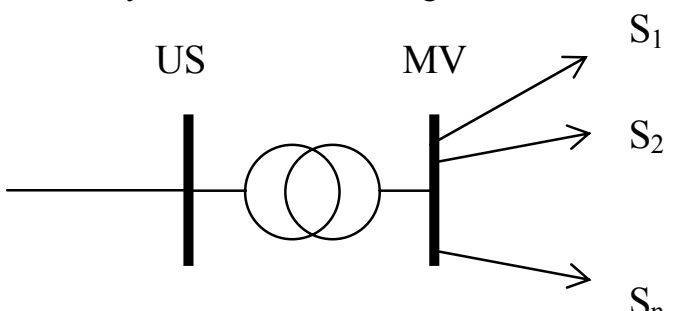

Fig. 1. Distribution system showing MV subsystem and upstream supply

It is assumed that the upstream system US, which may be $\mathrm{HV}$ or a higher level MV system, has reached its planning level $\mathrm{L}_{\mathrm{hus}}$ and can be represented by a harmonic source of this magnitude. Since the MV system is limited to its planning level $\mathrm{L}_{\mathrm{hMV}}$, the voltage available for the total MV load $\mathrm{S}_{\mathrm{t}}$ is, making use of (1),

$$
\mathrm{G}_{\mathrm{hMV}}=\sqrt[\alpha]{\mathrm{L}_{\mathrm{hMV}}^{\alpha}-\mathrm{L}_{\mathrm{hUS}}^{\alpha}}
$$

The effects of transfer coefficient and LV loads are ignored in this discussion to simplify the presentation. $\mathrm{E}_{\mathrm{Uhi}}$ is the harmonic voltage emission for load $S_{i}$ which can be determined, again making use of the diversity equation (1) as

$$
\mathrm{E}_{\text {Uhi }}=\left(\mathrm{S}_{\mathrm{i}} / \mathrm{S}_{\mathrm{t}}\right)^{1 / \alpha} \mathrm{G}_{\mathrm{hMV}}
$$

The corresponding harmonic current emission is

$$
\mathrm{E}_{\mathrm{Ihi}}=\mathrm{E}_{\mathrm{Uhi}} / \mathrm{Z}_{\mathrm{hi}}
$$

where $Z_{h i}$ is the harmonic impedance at the point of connection of load $\mathrm{S}_{\mathrm{i}}$. For distribution systems without capacitor resonance, this can be well approximated by $\mathrm{h}$ times the fundamental short-circuit reactance. Where the distribution system has short feeders, $Z_{\mathrm{hi}}$ will be relatively small. If all the loads at the supply point take their full allocation, it is possible that the supply harmonic current will be very large.

Determination of $\mathrm{G}_{\mathrm{hMV}}$ requires differentiation across $\mathrm{MV}$ planning levels where one MV system supplies another. Reference [1] only gives one suggested value for all MV levels. One of the purposes of [2] was to suggest a differentiation and this is shown in Table I giving one value for $33 \mathrm{kV}$ levels and another for $11 \mathrm{kV} / 22 \mathrm{kV}$.

\section{TRANSMISSION SYSTEM HARMONIC ALLOCATION}

Stage 2 allocation for transmission system has been undertaken by the authors and reported in [3]. It is more complex and less precise than distribution harmonic allocation because of the following factors

- Meshed configuration causes greater interaction difficult to break up into non-interacting subsystems needs to be studied as a single system

- Line capacitance significant, causing resonances in harmonic impedances and the influence of a load on remote nodes

- Always changing because of varying generator allocations and at a slower timescale the switching of lines, transformers etc, load variations

Because of the continuous changes, it is useful to some extent to think of the system for modelling purposes as undergoing a transition through a number of fixed parameter scenarios. The difficulties caused by these scenarios cannot be exaggerated. Although any one scenario can be modelled, choosing the scenarios to be modelled is very difficult. Once a set of scenarios has been chosen, it is also necessary to decide the proportion of time that each scenario holds. Line capacitance can mean that a slight change in scenario gives a major change in system behaviour because of a sharp resonance. The assumption in [1] that all loads deserve harmonic current leads to their representation as harmonic current sources for these studies. This assumption increases the chance of analysis giving sharp resonances since it removes the possibility of load damping from the computer 
model.

As a result of these uncertainties, complex computer studies do not allow precise allocation studies to be made. It is inevitable that simplifying assumptions have to be made giving uncertainty, so a greater safety margin has to be built into transmission allocation compared with distribution allocation. It appears to be inevitable that the transmission system cannot be as fully utilised for harmonic absorption as much as the distribution system.

We now give a summary of the transmission allocation method proposed in [3]. The approach is based on the allocation of harmonic voltage to each load in the transmission system based on

$$
\mathrm{E}_{\mathrm{Uhi}}=\mathrm{k}_{\mathrm{h}} \mathrm{S}^{1 / \alpha}
$$

where $\mathrm{k}_{\mathrm{h}}$ is the allocation constant. The exponent term allows for diversity - that is to give more harmonic current, relative to rating, for smaller loads. A load $S_{i}$ is then given the same allocation whether the allocation is made to the whole or to the parts and then combined.

Reference [3] shows that it is difficult to determine $k_{h}$ with confidence based on modelling several system scenarios. A simpler approach is to consider the maximum load $\mathrm{S}_{\max }$ in the transmission system. One can have more confidence that it will give the largest contribution to the harmonic voltage at its point of connection than for lesser loads. It is assumed that it gives a harmonic voltage of $50 \%$ of the planning level, giving

$$
0.5 \mathrm{~L}_{\mathrm{hHV}}=\mathrm{k}_{\mathrm{h}} \mathrm{S}_{\max }^{1 / \alpha}
$$

from which the allocation constant can be determined. The equation is to be applied at all nodes and can be used for present loads or future ones. The calculated valued of $\mathrm{k}_{\mathrm{h}}$ can be used until the transmission system has an upgrade sufficient that a larger value of $\mathrm{S}_{\max }$ can be considered.

Note the degree of conservatism in the assumption of $50 \%$ of the planning level to the local load. Because of diversity, the remote loads can take up more than half the planning level, equal to $\left(1-0.5^{\alpha}\right)^{(1 / \alpha)}=70 \%$ for $\alpha=1.4$ and $87 \%$ at higher harmonics where $\alpha=2$.

The voltage allocation $\mathrm{E}_{\text {Uhi }}$ has no immediate meaning to a customer who would have a much greater appreciation for a harmonic current allocation. There is thus need to estimate the harmonic impedance at the connection point for the load $\mathrm{S}_{\mathrm{i}}$. For a fixed scenario, this impedance varies in a complex manner with frequency because of the resonance of line capacitance with additional complexity due to lumped capacitors and the neglect of load damping. With a reasonable number of scenarios, there is a large rang of values for the harmonic impedance at a point and it is important to make a pessimistic choice of the larger values. Reference [1] shows that, for the lower frequencies, the value given in (7) is a good estimate of the upper bound of $Z_{\mathrm{hi}}$ :

$$
\mathrm{Z}_{\text {hi.max }}=2 \mathrm{hZ}
$$

where $Z_{1}$ is the fundamental value obtained from fault level considerations. Hence the allocated current should be

$$
\mathrm{E}_{\mathrm{Ihi}}=\mathrm{E}_{\mathrm{Uhi}} / \mathrm{Z}_{\text {hi.max }}
$$

\section{HARMONIC CURRENT ALLOCATION AT THE TRANSMISSION/DISTRIBUTION INTERFACE}

Fig. 2 shows part of a transmission system with a large installation $S_{1}$ and a distribution bulk supply point with rating $\mathrm{S}_{2}$

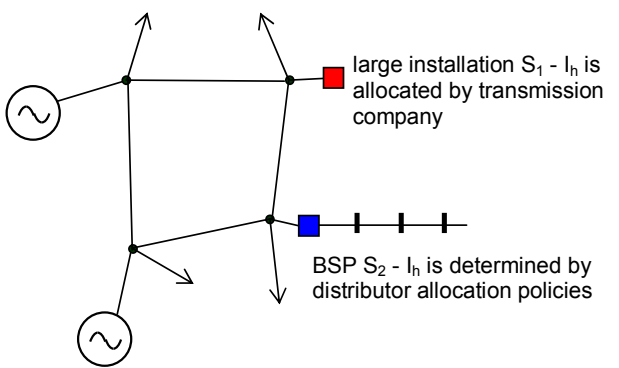

Fig.2. Transmission system with large installation $\mathrm{S}_{1}$ and distribution bulk supply point $\mathrm{S}_{2}$

The allocation to $\mathrm{S}_{1}$ will be based on transmission considerations. In many situations, the transmission company will have no agreement regarding harmonic voltages handed downstream to the distributor or harmonic currents which are passed upstream from distributor to transmission company. The harmonic current drawn by $\mathrm{S}_{2}$ will be the result of distribution allocation procedures being applied to all the loads supplied by $\mathrm{S}_{2}$. If $\mathrm{S}_{2}$ supplies only a few large loads all connected close to the secondary busbar of $\mathrm{S}_{2}$, it is possible that this current could be larger than what $S_{2}$ would receive as a transmission load. This could lead to the situation where the transmission company is unable to meet its planning levels at some connection points. This could lead to damage to nearby customers such as $\mathrm{S}_{1}$, especially if there are passive filters connected with small safety margins, or to a breach of contract where the transmission company has given an obligation to meet its harmonic planning levels. To check for this possibility, the two allocation processes will be applied to a case study selected to be typical of Australian conditions.

To investigate the worst case scenario, Fig. 3 shows an example bulk supply point where all the load may be considered as a single installation concentrated at the secondary MV busbar.

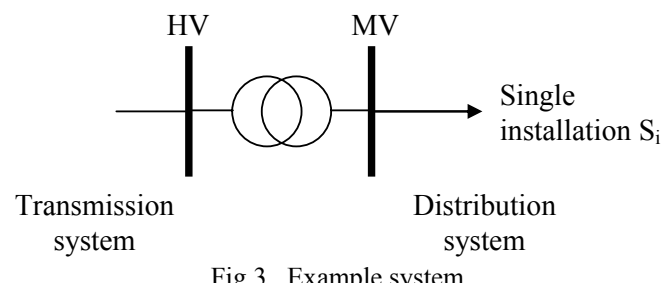

Representative parameter values are given in Table II.

TABLE II

PARAMETER VALUES FOR THE SYSTEM OF FIG.3

\begin{tabular}{|c|c||c|c|}
\hline Parameter & Value & $\begin{array}{c}\text { Paramete } \\
\mathbf{r}\end{array}$ & Value \\
\hline $\mathrm{S}_{\max }$ & $1,000 \mathrm{MVA}$ & $\mathrm{h}$ & 5 \\
\hline $\mathrm{S}_{\mathrm{i}}$ & $300 \mathrm{MVA}$ & $\alpha$ & 1.4 \\
\hline Fault level at HV bus & $3,000 \mathrm{MVA}$ & $\mathrm{L}_{\mathrm{hHV}}$. & $2 \%$ \\
\hline Fault level at MV bus & $1,000 \mathrm{MVA}$ & $\mathrm{L}_{\mathrm{hMV}}$. & $3.1 \%$ \\
\hline
\end{tabular}


Appendix A shows the different $5^{\text {th }}$ harmonic currents which would be allocated to the installation $S_{i}$ of maximum demand 300MVA depending on whether it be considered a distribution load with connection point at the MV busbar or a transmission load with connection point at the HV busbar. As a distribution connected load it would be allocated $1.2 \%$ relative harmonic current, while as a transmission connected load it would be allocated one third of this or $0.4 \%$ relative harmonic current.

A large customer emitting a current 3 times higher than is allocated under the proposed transmission allocation method can in some situations cause transmission harmonic voltages to exceed planning levels. The conditions needed would be

- Significant proportion of transmission customers taking their full harmonic current allocation

- Close coupling between the customer pcc and some other nodes in the transmission system where there is a high harmonic loading.

Hence the discrepancy between the two allocation approaches is expected to lead occasionally to high harmonic levels in the transmission system and it is worth attempting to understand why the discrepancy occurs and how to remove it.

The reason for the disparity is the different modelling approaches used with transmission and distribution systems. Distribution systems have reasonably well defined characteristics at harmonic frequencies (providing there are no uncompensated capacitors influencing the system) and it is possible to allocate harmonic currents with only a small safety margin. Transmission system harmonic characteristics are less certain. As a result, a large safety factor has to be allowed in transmission system harmonic allocation. A factor of about 4 comes about because of

- A factor of 2 to allow for uncertainty in the system harmonic resonance at the pcc

- A factor of 2 to allow for the contributions of remote loads at the pcc.

It might be asked why this problem has not been reported elsewhere. For the problem to become apparent, it would require every load supplied by a Bulk Supply Point (or some similar substation supplied from EHV-HV) to be very close to the supply terminals so that a reasonable harmonic voltage allocation becomes converted to a high harmonic current allocation. This is unlikely if the BSP supplies a normal distribution system having the majority of loads fed through several zone substations. It is unlikely that every load is close to the zone substation supply terminals and it is also unlikely that every load is taking its full harmonic allocation. The most likely scenario for the voltage level mismatch problem to arise is at a BSP with one or two major loads taking up most of the supply capacity and connected right at the BSP supply terminals.

Transmission systems are reported as having harmonic voltages higher than planning levels at some connection points at some frequencies, but insufficient is reported to know if it is because of the mismatch problem or because of some customer exceeding their harmonic allocation. For example [5] reports the result of a survey of $70 / 150 \mathrm{kV}$ sites. Harmonic planning levels are exceeded at some sites for some harmonics in the range 11-37 but there have been no reports of interference. Another [6] reports a harmonic survey of 28 substations in a $69 / 315 \mathrm{kV}$ transmission system. Planning levels were exceeded at some sites at the $5^{\text {th }}, 11^{\text {th }}, 23^{\text {rd }}, 25^{\text {th }}$, $35^{\text {th }}$ and $37^{\text {th }}$ harmonics.

In both cases, no adverse effects were reported. This is because the main reason for EHV-HV planning levels is to ensure that LV compatibility levels are not exceeded at LV. Harmonic levels here depend to some extent on transmission system levels, but more importantly on the harmonic emission of loads in the local distribution system.

\section{MODIFICATION TO THE ALLOCATION PROCESS TO REMOVE THE DISCREPANCY}

Three approaches of increasing complexity are examined for removing the allocation discrepancy. In the first, a maximum value is applied to the harmonic current allocation in situations where high transmission harmonic voltages might arise. The Hybrid allocation approach breaks large loads up into two parts, one part of which is treated as distribution connected and the other part as transmission connected. The adjustment of planning levels is examined since their selection is considered to be the root cause of the allocation discrepancy.

\section{A. Capped harmonic allocation}

For every harmonic allocation in a distribution system, one would need to consider the equivalent allowable transmission system absorption at the supply point and apply this as a cap. It would be convenient if a simple test could be developed that would guide when capping need to be applied. It may require experience with several cases in which the allocation discrepancy is a serious concern before such a test could be reliably developed. For this reason, this approach is not considered further here.

\section{B. Hybrid harmonic allocation}

The proposed solution is to try to find a simple rule-ofthumb which would identify when a problem is likely to occur and introduce a modification to the allocation procedure for this case. We consider only large loads which are connected one level down from the transmission system. We define a value $S_{\text {scrit }}$, the maximum such load which is to be given an unmodified distribution system harmonic allocation. Appendix B.A suggests that a value might be $5 \%$ of the maximum MVA which is would be connected directly to the transmission system. For loads $\mathrm{S}_{\mathrm{i}}$ greater than $\mathrm{S}_{\text {crit }}$, a two part harmonic allocation is given

- The part $\mathrm{S}_{\text {crit }}$ is given an allocation by a distribution approach.

- The part $\left(\mathrm{S}_{\mathrm{i}}-\mathrm{S}_{\text {crit }}\right)$ is given an allocation by a transmission approach

- The two parts are combined using the Summation Law 
Appendix B.B gives detailed equations for applying this approach.

The strategy of giving a straight transmission approach to all loads greater than $\mathrm{S}_{\text {crit }}$ was also considered. This requires less calculation then the above method and appears attractive at first. However, consider loads $S_{1}$, just less than $S_{\text {crit }}$ and load $S_{2}$ just greater than $S_{\text {crit. }}$ With this strategy, $S_{2}$ would receive as little as $1 / 3$ of what was allocated to $S_{1}$, even when it was only slightly larger. This anomaly is removed by the two part allocation scheme recommended.

The proposed approach has been applied to the example discussed in Section VI.A, where a 300MVA load was allocated $1.2 \%$ harmonic current by distribution principles and $0.4 \%$ harmonic current by transmission principles. In the new approach, detailed in Appendix B.B, with $\mathrm{S}_{\max }=1,000 \mathrm{MVA}$ and $\mathrm{S}_{\text {crit }}$ taken as 50MVA, the load would be allocated $0.6 \%$ harmonic current.

In cases where this modified allocation may give problems to the customer, it can be given more for a temporary period under a transmission system Stage 3 allocation policy. This should involve a pre-connection and post-connection harmonic monitoring campaign.

\section{Adjusted planning levels}

The distribution of harmonic allocation between the different voltage levels depends on the profile of the planning levels from EHV-HV down to MV and LV. A fundamental approach is to adjust the planning levels to allow less harmonic current in the distribution system and more in the transmission system. This would mean increasing the planning levels at the higher voltage levels. This may be a good long term solution, but it probably requires an extensive study of the original IEC methodology before a recommendation can be given which has no other adverse side-effects.

Some insight can be gained by applying this idea to the example of Fig. 3. The transmission allocation is directly affected by the HV planning level of $2 \%$ (A.2 Step 1). The distribution allocation is affected by the more complex expression involving both $\mathrm{HV}$ and $\mathrm{MV}$ planning levels: $\sqrt[\alpha]{3.1^{\alpha}-2^{\alpha}}$ (A.1 Step 1). The ratio of the present allocations is determined by the ratio $\sqrt[\alpha]{3.1^{\alpha}-2^{\alpha}} / 2$ and is three times larger than desirable. Suppose we keep the MV planning level constant at $3.1 \%$ and change the $\mathrm{HV}$ planning level from its

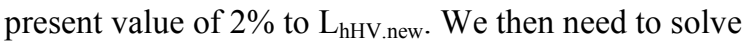

$$
\frac{\sqrt[\alpha]{3.1^{\alpha}-\mathrm{L}_{\text {hHV.new }}^{\alpha}}}{\mathrm{L}_{\text {hHV..new }}}=\left(\frac{1}{3}\right) \frac{\sqrt[\alpha]{3.1^{\alpha}-2^{\alpha}}}{2}
$$

from which $\mathrm{L}_{\mathrm{hHV} \text {.new }}=2.75 \%$, rather higher than the present $2 \%$. It is worth noting that there are several papers which state that their harmonic voltages are larger than the present planning levels with no apparent harm [5], [6] and an increase in HV planning levels would appear to be welcomed.

We now investigate how these new planning levels would affect harmonic allocation. The increase in HV allocation would be in the ratio of 2.75 to 2 or $138 \%$. The reduction in $\mathrm{MV}$ allocation is to a value $46 \%$ of the old. New planning levels based on this idea would reduce MV allocations more than the increase in transmission allocation, so the net harmonic absorption of the power system would be reduced for the benefit of better control over transmission system harmonic levels.

\section{CONCLUSIONS}

It has been shown how the principles of [1] can be applied to both distribution and transmission systems. The different nature of the two types of systems means the adoption of somewhat different allocation methodologies, with greater certainty and less need for a safety margin for distribution systems. As a result, there is a discrepancy between the two allocation methods which is highlighted at the transmission/distribution interface. The discrepancy is in favour of the distribution system and there is a risk of transmission harmonic levels being exceeded as a consequence.

Three methods of resolving the discrepancy are discussed. The one which seems to offer a simple solution is a hybrid allocation approach applied to loads of sufficiently large size. A more fundamental approach is a review of planning levels. This will lead to a reduction in the overall harmonic absorption of power systems, and should only be pursued if the allocation discrepancy is found to be widespread with the present values.

\section{ApPendix A - Detailed calculation of Allocation}

Refer to Fig. 3 and Table II for the system under study and its parameters.

\section{A. Distribution system allocation}

Choose a base $\mathrm{S}_{\text {base }}=100 \mathrm{MVA}$

1. Determine $G_{M V . h}$, the harmonic voltage available for loads connected to the MV system

$$
\mathrm{G}_{\mathrm{MV} . \mathrm{h}}=\sqrt[\alpha]{\mathrm{L}_{\mathrm{MV} . \mathrm{h}}{ }^{\alpha}-\mathrm{L}_{\mathrm{HV} . \mathrm{h}}{ }^{\alpha}}=\sqrt[1.4]{3.1^{1.4}-2.0^{1.4}}=1.78 \%
$$

In this case, this is all allocated to $\mathrm{S}_{\mathrm{i}}$. Hence

$$
\mathrm{E}_{\text {Uhi }}=1.78 \%
$$

2. Determine the harmonic impedance as seen from the MV system

$$
\begin{aligned}
\mathrm{Z}_{\mathrm{li}}= & \mathrm{S}_{\mathrm{base}} / \mathrm{FL}_{\mathrm{MV}}=100 / 1,000=0.1 \mathrm{pu} \\
& \mathrm{Z}_{5 \mathrm{i}}=\mathrm{hZ}_{1 \mathrm{i}}=5 \times 0.1=0.5 \mathrm{pu}
\end{aligned}
$$

3. Find the harmonic current to be allocated to load $\mathrm{S}_{\mathrm{i}}$ $\mathrm{E}_{\mathrm{Ihi}}=\mathrm{E}_{\mathrm{Uhi}} / \mathrm{Z}_{\mathrm{hi}}=1.78 / 0.5=3.56 \%(100 \mathrm{MVA}$ base $)$ or $1.19 \%$

\section{B. Transmission system allocation}

Choose a base $\mathrm{S}_{\text {base }}=100$ MVA, giving $\mathrm{S}_{\max }=10 \mathrm{pu}$ and $\mathrm{S}_{\mathrm{i}}=3 \mathrm{pu}$.

1. Determine the harmonic allocation constant $\mathrm{k}_{\mathrm{h}}$

$$
\mathrm{k}_{\mathrm{h}}=0.5 \mathrm{~L}_{\mathrm{HV} . \mathrm{h}} / \mathrm{S}_{\max }^{1 / \alpha}=0.5 \times 2 \% / 10^{1 / 1.4}=0.0019
$$

2. Determine the harmonic voltage to be allocated to load $\mathrm{S}_{\mathrm{i}}$

$$
\mathrm{E}_{\text {Uhi }}=\mathrm{k}_{\mathrm{h}} \mathrm{S}_{\mathrm{i}}{ }^{1 / \alpha}=0.0019 \times 3^{1 / 1.4}=0.42 \%
$$

3. Estimate the maximum value of the harmonic impedance at the pcc for load $S_{i}$.

$$
\begin{gathered}
\mathrm{Z}_{1 \mathrm{i}}=\mathrm{S}_{\text {base }} / \mathrm{FL}_{\mathrm{i}}=100 / 3000=0.033 \mathrm{pu} \\
\mathrm{Z}_{\text {hi.max }} \sim 2 \mathrm{hZ} \mathrm{Z}_{1 \mathrm{i}}=2 \times 5 \times 0.033=0.333 \mathrm{pu}
\end{gathered}
$$


4. Find the harmonic current to be allocated to load $\mathrm{S}_{\mathrm{i}}$

$\mathrm{E}_{\mathrm{Ihi}}=\mathrm{E}_{\mathrm{Uhi}} / \mathrm{Z}_{\mathrm{hi} \text { max }}=0.42 \% / 0.333=1.26 \%(100 \mathrm{MVA}$ base) or $0.42 \%$

In this case, we see that the load has a harmonic current allocated to it on the distribution side of almost three times what it would be allocated from the transmission side.

\section{APPENDIX B - HYBRID ALLOCATION METHOD}

\section{A. Minimum load $S_{\text {crit }}$ to be given by distribution allocation}

In the example, it was found that a single load of 300MVA was allocated a harmonic current about 3 times more than such a load deserved from transmission considerations. Suppose that this load was reduced, and the rest of the load had negligible distortion. How small would the load $S_{i}$ have to be in order for the distribution allocation to be acceptable to the transmission system? If there was no diversity, we would have to solve

$$
\left(\mathrm{S}_{\mathrm{i}} / 300\right)=0.33
$$

Because of diversity, instead we have to solve

$$
\left(\mathrm{S}_{\mathrm{i}} / 300\right)^{1 / \alpha}=0.33
$$

Setting $\alpha$ to 1.4 (valid for harmonics in the range 5-10) gives

$$
\mathrm{S}_{\mathrm{i}}=63 \mathrm{MVA}
$$

Based on this rough calculation, it is recommended that $\mathrm{S}_{\text {crit }}$ is taken as $5 \%$ of the maximum transmission load (giving 50MVA in this case). Loads greater than $\mathrm{S}_{\text {crit }}$ and connected to the distribution system will need to be given a modified harmonic allocation procedure.

\section{B. Allocation scheme for large loads connected to distribution systems}

Suppose the critical value of load is $S_{\text {crit }}$. The proposed allocation strategy to overcome voltage level mismatch is to allocate by distribution principles to loads less than $\mathrm{S}_{\text {crit }}$ and to allocate to loads more than this by transmission principles. As explained in Section V, this has to be implemented by a two part approach, breaking a load up into parts $S_{\text {crit }}$ and $S_{i}-S_{\text {crit }}$.

Suppose, for $S_{i}$, we have allocated harmonic currents $I_{\text {hi.d }}$ and $I_{\text {hi.t }}$ by distribution and transmission approaches respectively. The distribution allocation to $\mathrm{S}_{\text {crit }}$ can be found by proportion, allowing for diversity by the Summation Law.

$$
\mathrm{I}_{\text {h.crit.d }}=\left(\mathrm{S}_{\text {crit }} / \mathrm{S}_{\mathrm{i}}\right)^{1 / \alpha} \mathrm{I}_{\text {hi.d }}
$$

Hence the two components of current allocated to $S_{i}$ are, for the $\mathrm{S}_{\text {crit }}$ part of it

$$
\mathrm{I}_{\text {hi1 }}=\mathrm{I}_{\text {h.crit.d }}
$$

For the remainder of it $\mathrm{S}_{\mathrm{i}}-\mathrm{S}_{\text {crit }}$, using proportion and the Summation Law-

$$
\mathrm{I}_{\text {hi2 }}=\left(\left(\mathrm{S}_{\mathrm{i}}-\mathrm{S}_{\text {crit }}\right) / \mathrm{S}_{\mathrm{i}}\right)^{1 / \alpha} \mathrm{I}_{\text {hi.t }}
$$

The allocated harmonic current is found by combining (B.2) and (B.3) with a diversity allowance

$$
\mathrm{I}_{\text {hi }}{ }^{\alpha}=\mathrm{I}_{\text {hi1 }}{ }^{\alpha}+\mathrm{I}_{\text {hi2 }}{ }^{\alpha}=\left(\mathrm{S}_{\text {crit }} / \mathrm{S}_{\mathrm{i}}\right) \mathrm{I}_{\text {hi.d }}{ }^{\alpha}+\left(\left(\mathrm{S}_{\mathrm{i}}-\mathrm{S}_{\text {crit }}\right) / \mathrm{S}_{\mathrm{i}}\right) \mathrm{I}_{\text {hi.t }}{ }^{\alpha}
$$

$$
\text { giving } \quad \mathrm{I}_{\text {hi }}=\sqrt[\alpha]{\mathrm{I}_{\text {hi.t }}{ }^{\alpha}+\left(\mathrm{S}_{\text {crit }} / \mathrm{S}_{\mathrm{i}}\right)\left(\mathrm{I}_{\text {hi.d }}{ }^{\alpha}-\mathrm{I}_{\text {hi.t }}{ }^{\alpha}\right)}
$$

To check that this law gives the right effect, we substitute

$\mathrm{S}_{\mathrm{i}}=\mathrm{S}_{\text {crit, }}$ giving $\mathrm{I}_{\text {hi.d }}$, a simple distribution allocation as required. We also note that, in the limit for large $S_{i}$, the expression approaches $\mathrm{I}_{\text {hi.t, }}$, again as required.

\section{Example of allocation to large load}

In the previous example, for $\mathrm{S}_{\mathrm{i}}=300 \mathrm{MVA}, \mathrm{I}_{\text {hi.d }}=1.2 \%$ and $\mathrm{I}_{\text {hi.t }}=0.4 \%$. Assuming $\mathrm{S}_{\max }=1,000 \mathrm{MVA}, \mathrm{S}_{\text {crit }}=5 \%$ of $\mathrm{S}_{\max }$ or 50 MVA.

$$
\mathrm{I}_{\text {hi }}=\sqrt[\alpha]{\mathrm{I}_{\text {hi.t }}{ }^{\alpha}+\left(\mathrm{S}_{\text {crit }} / \mathrm{S}_{\mathrm{i}}\right)\left(\mathrm{I}_{\text {hi.d }}{ }^{\alpha}-\mathrm{I}_{\text {hi.t }}{ }^{\alpha}\right)}=0.6 \%
$$

\section{REFERENCES}

[1] International Electrotechnical Commission. IEC/TR 61000-3-6. "Electromagnetic compatibility (EMC) - Part 3: Limits - Section 6: Assessment of emission limits for distorting loads in MV and HV power systems - Basic EMC publication" (Technical report - Type 3. First edition. October 1996.)

[2] Standards Australia. HB 264-2003 "Power quality - Recommendations for the application of AS/NZS 61000.3.6 and AS/NZS 61000.3.7" (August 2003)

[3] T.J. Browne, V.J. Gosbell, S. Perera, D.A. Robinson, L.M. Falla, P.J. Windle, A.C.D. Perera, "Experience in the application of IEC/TR 610003-6 to harmonic allocation in transmission systems", CIGRE, Paris, September, 2006, Paper C4-401

[4] IEC 61000-4-7 "Part 4-7: Testing and measurement techniques General guide on harmonics and interharmonics measurements and instrumentation, for power supply systems and equipment connected thereto", 2nd Edition 2002.

[5] G. Borloo, E. De Jaeger, M. Dussart and A. Robert, "Practical implementation of IEC publications 1000-3-6 and 1000-3-7. Experiences in Belgium", Proc. International Conference on Harmonics and Quality of Power, Athens, 1998, pp. 449454

[6] G. Beaulieu, "Planning levels and harmonic measurements on HydroQuebec's transmission system", Proc. International Conference on Harmonics and Quality of Power, Athens, 1998, pp. 445-448

\section{BIOGRAPHIES}

Vic Gosbell (M'1975) obtained his BSc, BE and PhD degrees from the University of Sydney. He has held academic positions at the University of

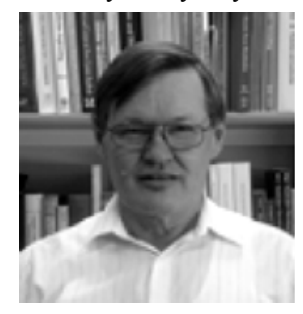

Engineers, Australia.

Timothy Browne (StM '02, M '07) holds the B. E. (Hons) degree in Electrical Engineering from the University of New South Wales and has completed the Ph.D. degree at the University of Wollongong. He is presently with Arizona State University.

Sarath Perera (M'96) received the B.Sc.(Eng.) degree in power from the University of Moratuwa, Sri Lanka, in 1974, the M.Eng.Sc. degree from the University of New South Wales in 1978, and the Ph.D. degree from the University of Wollongong in 1988. He was a Lecturer for twelve years with the University of Moratuwa. Currently he is an Associate Professor with the University of Wollongong and is the Technical Director of the Integral Energy Power Quality and Reliability Centre. His research interests are in power quality. 